\title{
Diurnal Ghanges in the Concentrations of Micro-organisms in the Rumens of Sheep Fed to Appetite in Pens or at Pasture
}

\author{
By A. C. I. WARNER \\ C.S.I.R.O., Division of Animal Physiology, Ian Clunies Ross Animal Research \\ Laboratory, Prospect, N.S.W., Australia
}

(Received 14, December 1965)

\section{SUMMARY}

The concentrations of the various groups of micro-organisms in the rumens of sheep when feeding on a roughage diet to appetite or grazing a mixed pasture, changed with time in patterns very similar to those previously found in sheep fed restricted diets once daily. It is postulated that these patterns will be present wherever the daily eating behaviour of the animal includes a major fairly continuous period during which all or most of the ration is eaten, and long periods during which little or no feed is consumed.

\section{- INTRODUCTION}

In the previous papers in this series (Warner, 1966a,b), I examined the changes in concentration of the micro-organisms in the rumens of sheep following the giving of restricted amounts of feed which were consumed promptly. However, in natural circumstances and under farming conditions, most ruminants have virtually unlimited amounts of feed available and may choose their own times and rates of eating. To gain information about the rumen microbial population under more natural conditions, studies were made of the micro-organisms from the rumens of two sheep grazing with unrestricted access to a mixed pasture and two sheep offered a dry roughage diet ad libitum. The patterns of change of concentration for the various groups of micro-organisms were compared with the patterns found previously.

\section{METHODS}

Two English Leicester-Merino crossbred wethers (numbers 1330 and 2985) were fed wheaten chaff to appetite. Feed residues were removed at about $08.30 \mathrm{hr}$ and at $10.30 \mathrm{hr}$ a fresh batch of feed was presented; water was available at all times. At approximately 2 -hr intervals, rumen liquor samples were collected and the feed and water consumptions measured.

Two other sheep (numbers 1593 and 2750) were grazing in a flock of 8 sheep on a pasture consisting predominantly of Lolium perenne and Trifolium subterraneum. They were inspected at approximately $\frac{1}{2} \mathrm{hr}$ intervals and their grazing behaviour noted (Hull, Lofgreen, \& Meyer 1960). Water was available to the sheep, but they were not seen to drink; the pasture was fairly wet following recent spring rain. Rumen liquor samples were collected at approximately 2-hr intervals. 
The experiments were concurrent, i.e. all the samples were collected within one day.

Micro-organisms were identified and counted as described by Warner (1966a). The organisms described here as lampropedias were organism no. 25 of Moir \& Masson (1952), the 'window-pane sarcina', which is almost certainly related to Lampropedia hyalina as described by Pringsheim (1955) and Chapman, Murray \&
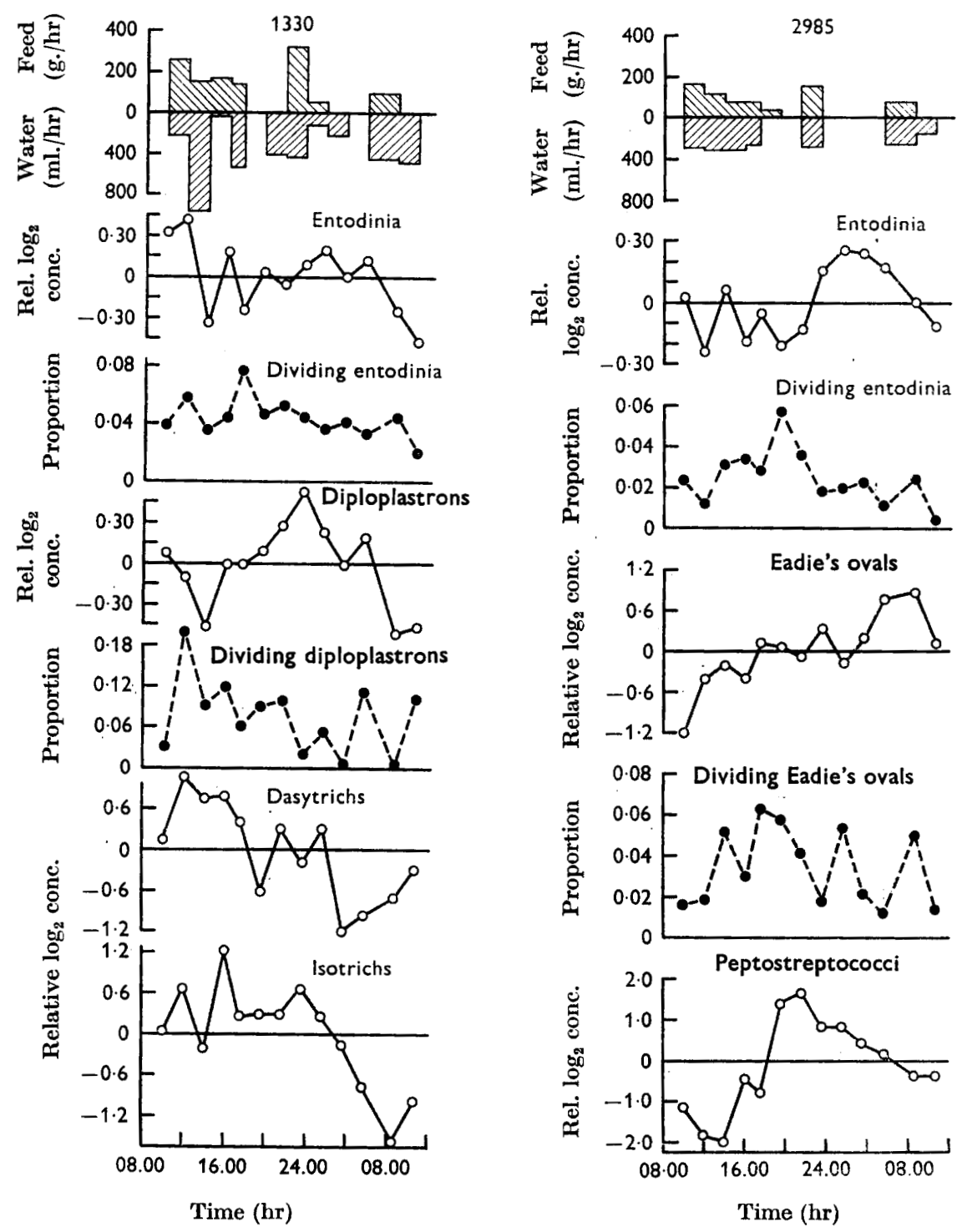

Fig. 1. Feeding and drinking behaviour and changes in rumen microbial population in sheep nos. 1330 and 2985, fed wheaten chaff to appetite. Basal concentrations in numbers/ ml. were as follows (data for sheep nos. 1330 and 2985, respectively): entodinia, $2 \cdot 3 \times 10^{5}$, $3.0 \times 10^{5}$; diploplastrons, $4.0 \times 10^{3}, 0$; dasytrichs, $2.3 \times 10^{3}, 0$; isotrichs, $2.4 \times 10^{3}, 0$; Eadie's ovals, $0,7 \cdot 7 \times 10^{6}$; peptostreptococci, $0,6.0 \times 10^{4}$. 
Salton (1963). These organisms were arranged in plates or sheets of moderately uniform size, and were counted as numbers of plates.

The graphical presentation of the data as relative $\log _{2}$ concentrations, with the basal concentrations given in the legends to the figures, has been described previously by Warner $(1966 a)$.
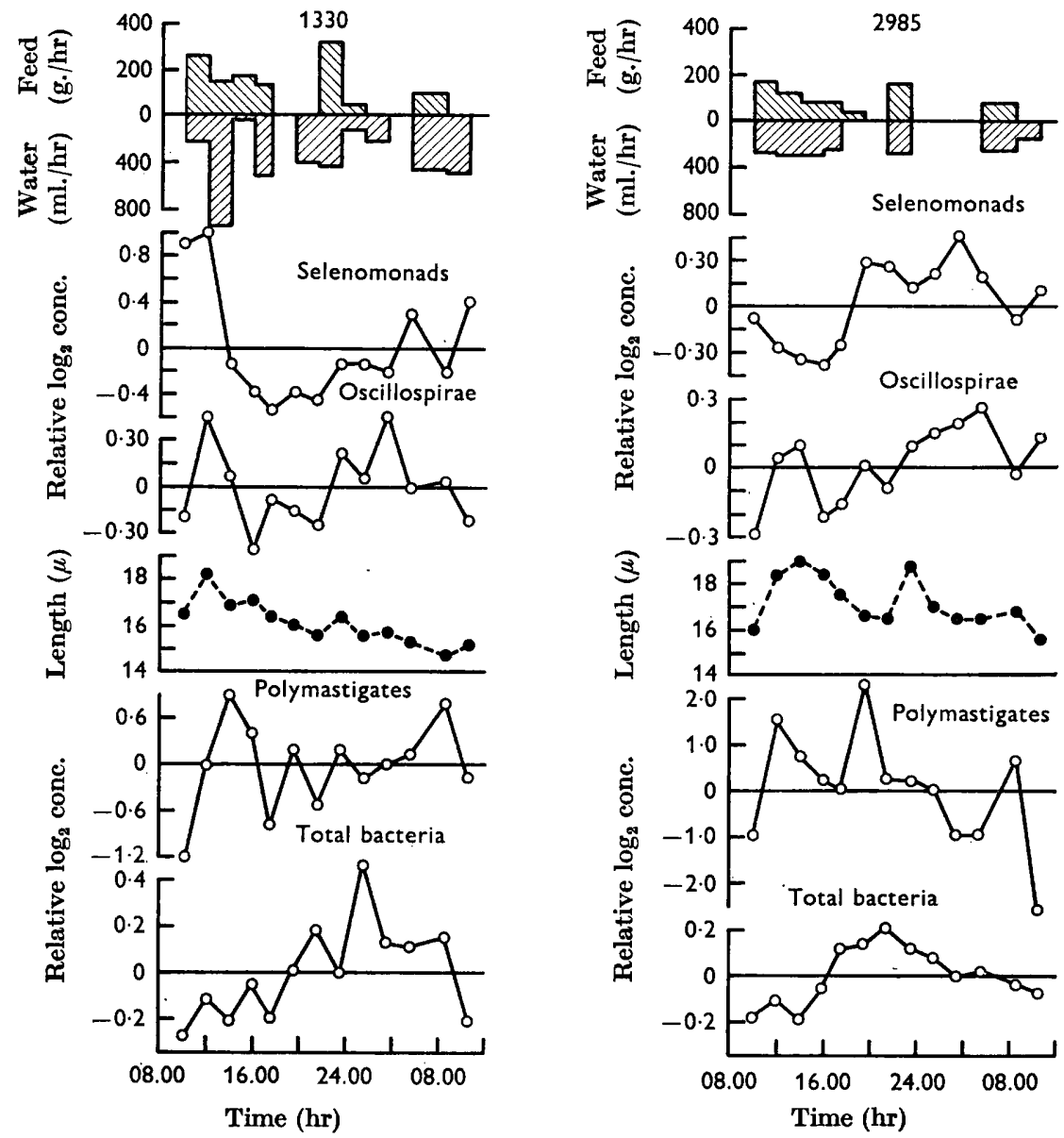

Fig. 2. Feeding and drinking behaviour and changes in rumen microbial population in sheep nos. 1330 and 2985, fed wheaten chaff to appetite. Basal concentrations in numbers/ ml. were as follows (data for sheep nos. 1330 and 2985, respectively): selenomonads, $1 \cdot 1 \times 10^{7}, 2 \cdot 4 \times 10^{8}$; oscillospirae, $1.1 \times 10^{8}, 3.9 \times 10^{7}$; polymastigates, $7 \times 10^{3}, 6 \times 10^{3}$; total bacteria, $2 \cdot 6 \times 10^{10}, 3 \cdot 3 \times 10^{10}$.

\section{RESULTS}

\section{Sheep fed dry roughage to appetite}

Results are shown in Figs. 1 and 2. Feed and water were consumed in three periods: a long period near the middle of the day (sheep no. 1330, weighing $73 \mathrm{~kg}$., ate 1360 g. feed, sheep no. 2985 , weighing $49 \mathrm{~kg}$., ate $820 \mathrm{~g}$.); a short period around midnight (feed consumed 740 and $290 \mathrm{~g}$., respectively); another short period early in the morning (feed consumed 310 and 205 g., respectively). In the first two periods the 
sheep drank water equivalent to 2-3 times the weight of the feed eaten, but in the last period the ratio was $6-7$ times.

The entodinia, diploplastrons and Eadie's ovals showed similar patterns of behaviour (Fig. 1), with lower concentrations but more actively dividing organisms

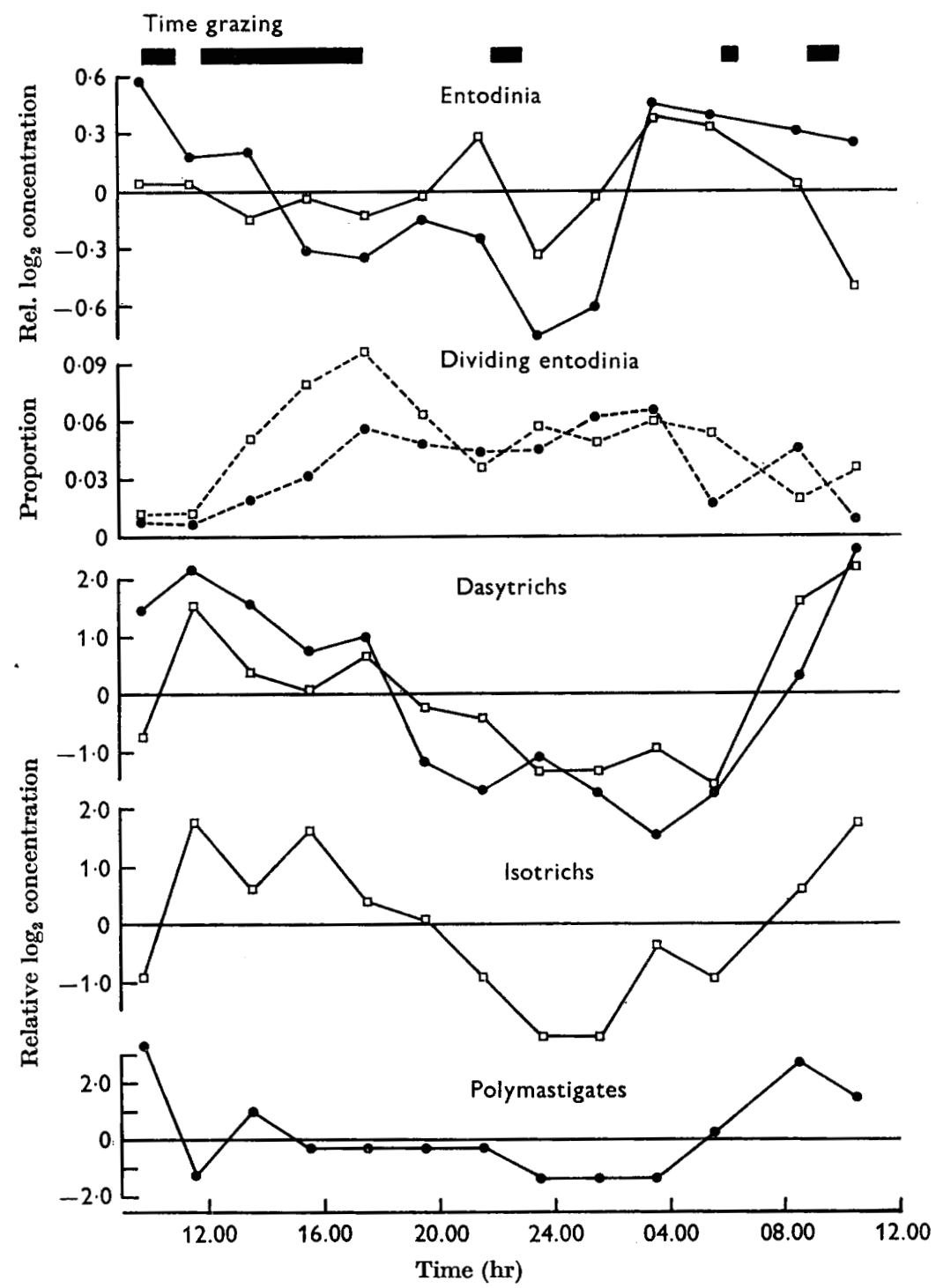

Fig. 3. Grazing behaviour and changes in rumen microbial population in sheep no. 1593 ( $\square$ ) and no. 2750 (๑). Basal concentrations in numbers $/ \mathrm{ml}$. were as follows (data for sheep nos. 1593 and 2750 , respectively): entodinia, $3.9 \times 10^{5}, 7 \cdot 3 \times 10^{5}$; dasytrichs, $1.5 \times$ $10^{4}, 3.9 \times 10^{4}$; isotrichs, $3.8 \times 10^{3}, 0$; polymastigates, $0,2.5 \times 10^{3}$.

when the animal was eating than when it was resting. The concentrations of selenomonads and total bacteria (Fig. 2) also tended to be greatest when the animal was resting. The peptostreptococci (Fig. 1) showed a considerable increase in concen- 
tration towards the end of the first eating period, but no further increase after later meals.

The polymastigates (Fig. 2) showed considerable increases in concentration during the midday and early morning feeds, but none during the midnight feed. The holotrich ciliate protozoa (Fig. 1) showed deep minima early in the morning. The oscillospirae (Fig. 2) showed two peaks in concentration, the first associated with

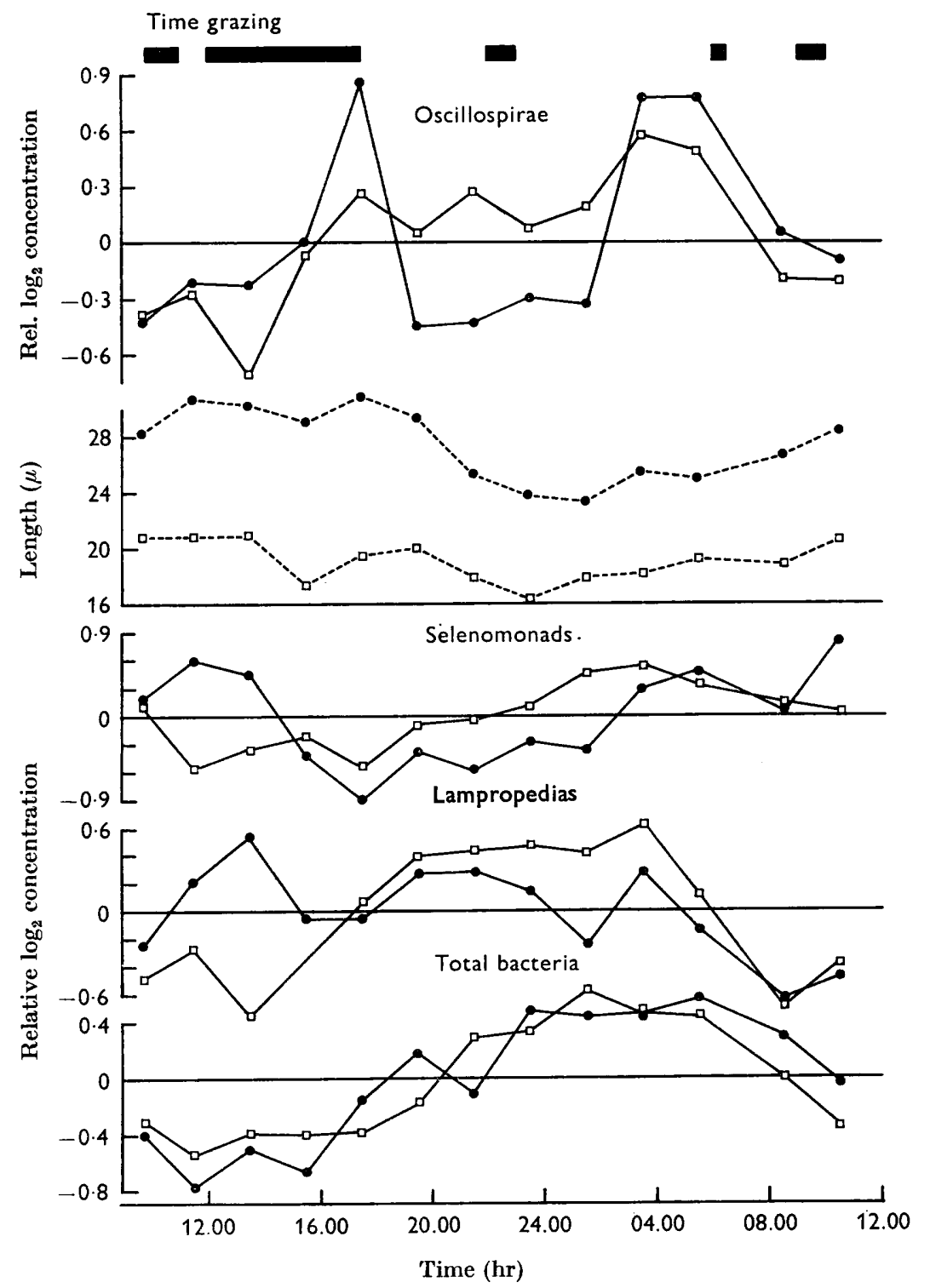

Fig. 4. Grazing behaviour and changes in rumen microbial population in sheep no. 1593 ( $\square$ ) and no. 2750 (๑). Basal concentrations in numbers $/ \mathrm{ml}$. were as follows (data for sheep nos. 1593 and 2750 , respectively): oscillospirae, $8.8 \times 10^{5}, 8.9 \times 10^{5}$; selenomonads, $1.6 \times 10^{8}, 6.6 \times 10^{8}$; lampropediae, $8.0 \times 10^{5}, 3.5 \times 10^{5}$; total bacteria, $3.7 \times 10^{10}$, $4.6 \times 10^{10}$. 
the midday feeding period, and with a peak in trichome length, the second early in the morning, associated with a generally decreasing trichome length.

\section{Grazing sheep}

Results are shown in Figs. 3 and 4. Assuming that the time spent grazing is a measure of the amount of feed consumed, these animals also consumed most of their feed during the middle of the day, with a short feeding period around midnight and another two short periods early in the morning. These sheep were not seen to drink.

The entodinia (Fig. 3) showed a decreasing or stationary concentration throughout the major grazing period and for a while thereafter, increasing rapidly in the early morning and then decreasing slowly again. The proportion of dividing entodinia increased during the major grazing period, particularly in sheep 1593, and then slowly decreased. Somewhat similar concentration changes were seen with the selenomonads and total bacteria (Fig. 4).

The concentration of lampropedias (Fig. 4) in sheep no. 1593 was low during the major grazing period, increasing rapidly to a high value which was maintained until early morning when the concentration decreased. A less regular behaviour was seen in sheep no. 2750. The polymastigates in both sheep were high in concentration early in the morning (Fig. 3) but low throughout the rest of the day. The holotrich ciliate protozoa (Fig. 3) reached maximal concentration shortly before noon, then slowly decreased in concentration to minima $12-18 \mathrm{hr}$ later.

The concentration of oscillospirae showed two well-marked peaks for sheep no. 2750 (Fig. 4), the afternoon peak being associated with maximal length of trichome, the early morning peak with near-minimal length. In sheep no. 1593 the concentration increased during the early afternoon as in sheep no. 2750, but did not decrease before the further increase in the early morning; the mean length of the trichomes was higher in the afternoon than in the early morning, but the differences were not as marked as for sheep no. 2750 .

\section{DISCUSSION}

Ruminants at pasture usually graze for 8-9 hr per day, and most of this time is spent in one major period of fairly continuous eating (Hughes \& Reid, 1951; Arnold, 1962). In the present work, both the grazing and the penned sheep spent a fairly continuous period of 6-9 hr consuming 60-80\% of their day's total feed. In the previous studies, the sheep needed only about $1 \mathrm{hr}$ to consume their whole ration, either in one continuous period (Warner, 1966a) or regularly distributed throughout the day (Warner, 1966 b).

The rumens of the sheep in the present studies were more tightly packed with feed than in the previous work, and hence the digesta were presumably less well mixed. Bearing in mind this inefficient mixing, the patterns of microbial concentration change appeared generally similar to those found in sheep fed once daily (Warner, 1966a), rather than to the patterns found in frequently fed animals (Warner, 1966b). Hence it would appear that the conditions which control microbial growth in the rumens of animals feeding naturally to appetite, whether in pens or at pasture, resemble those in animals fed a restricted diet once daily, presumably owing to the basic similarity of eating behaviour.

Dilution rates were not measured in the present experiments. However, since 
these animals ate more feed than the restricted ones, and since the amount of saliva secreted per unit of feed consumed is fairly constant (Bailey, 1961 ; Meyer, Bartley, Morril \& Stewart, 1964; Stacy \& Warner, 1966), it was expected that the dilution rates would be greater. Ulyatt (1964) found average dilution rates of $0 \cdot 10-0 \cdot 24 \mathrm{hr}^{-1}$ for animals grazing normal pastures; these values are somewhat higher than the figure of $0.06 \mathrm{hr}^{-1}$ found by Warner (1966a) for an animal on a restricted ration. Hogan (1964) also found greater flow rates through the rumens of grazing sheep and sheep fed to appetite than in animals on restricted rations. When considered over the full $24 \mathrm{hr}$, the dilution rate must equal the net growth rate of the micro-organisms, so that it was expected that the growth rates and hence the proportions of dividing organisms should be greater in the present work than previously. Table 1 shows that this expectation was realized. The magnitude of the difference suggests that the overall dilution rate was about double that found previously, i.e. was probably in the range $0 \cdot 10-0 \cdot 15 \mathrm{hr}^{-1}$, in both experiments. It seems likely that the dilution rate would not exceed $0 \cdot 1 \mathrm{hr}^{-1}$ except when the animal was actually eating.

The immediate effect of the act of eating on conditions in the rumen is a greatly increased dilution rate, rapidly followed by the leaching of solutes from the feed. At various, slower, rates, the metabolic products of the feed constituents then accumulate. The rumen micro-organisms respond to the incoming nutrients by growth, but usually after some delay. My previous work has shown that for some organisms many hours are needed for this response to develop fully, so that the characteristic pattern of concentration change is only shown when the animal spends long periods without eating.

Table 1. Average proportions of dividing organisms

$\begin{array}{lcccc}\text { Organism } & \overbrace{\text { Once daily* }}^{\text {Restricted ration }} & \text { 3-hourly } \dagger & \overbrace{\text { Chaff } a d \text { lib. }}^{\text {Unrestricted ration }} & \text { Grazing } \\ \text { Entodinia } & 0.018 & 0.018 & 0.035 & 0.045 \\ \text { Diploplastrons } & 0.050 & 0.033 & 0.075 & 0.09 \ddagger \\ \text { Polyplastrons } & 0.059 & - & 0.16 \ddagger & 0.10 \ddagger \\ \text { Eadie's ovals } & 0.033 & - & 0.035 & - \\ \text { Holotrichs§ } & 0.008 & 0.008 & 0.010 & 0.026\end{array}$

\footnotetext{
* Data taken from Warner $(1966 a)$; † Data taken from Warner $(1966 b)$; Data were not presented in Figs. 1-4 since concentrations were too low for accurate counts; the figure represents the proportion in the total of organisms counted; $\S$ These data were not reported previously but were taken from the same experiments.
}

As stated previously (Warner, $1966 a$ ) the concentration of organisms in the rumen can be affected by dilution, by division, by lysis and by sequestration and return. Lysis and sequestration do not appear to play any significant part in the behaviour of the ophryoscolecid protozoa, selenomonads, Eadie's ovals or lampropedias. The changes in the concentrations of the organisms appear to reflect only changes in dilution rate, e.g. in response to eating, and changes in growth rate, e.g. in response to the supply of nutrients. The curves for the entodinia in Fig. 3 show this particularly well, each feeding being accompanied by a decrease in concentration greater for the less actively dividing organisms, and by a slowly increasing rate of division. 
In this same experiment, the effect of the midnight feeding is not so noticeable with the selenomonads and lampropedias (Fig. 4); possibly their growth rates were still increasing in response to the previous feed. Again, in the penned animals, the most noticeable increases in concentration of these organisms occurred between feeding periods (Figs. 1, 2).

The rate of decrease of concentration of the peptostreptococci in the penned sheep no. 2985 (Fig. 1) after its maximum at about $21.00 \mathrm{hr}$ was greater than could be accounted for by the expected dilution rate $\left(r=-0.15 \mathrm{hr}^{-1}, D<0 \cdot 1 \mathrm{hr}^{-1}\right.$ so that the net growth rate $\rho$ was negative), suggesting as previously (Warner, 1966a) that lysis or engulfment was taking place. The rapid increase in concentration, beginning shortly after the major part of the day's ration had been consumed, was at a rate indicating a doubling time of about $2 \mathrm{hr}$, as before (Warner, $1966 \mathrm{a}$ ).

The polymastigate flagellates behaved somewhat irregularly, but most of the considerable increases in concentration followed closely on the start of a period of eating (Figs. 2, 3). This is consistent with the previous tentative explanation of normal sequestration close to the rumen wall with return to the general rumen liquor in response to fresh nutrients (Warner, 1966a).

The holotrich ciliate protozoa also showed long periods when the rates of decrease of concentration were greater than could be accounted for by the dilution rate (from Figs. 1 and 3, $r=-0.11$ to $-0.21 \mathrm{hr}^{-1}$ ). A minimum 14-22 $\mathrm{hr}$ after the beginning of the major feeding period was followed by a period of perhaps $8 \mathrm{hr}$ during which the organisms divided at least 2-4 times. Dividing organisms were more irregularly distributed than in the previous work, but again the highest proportions of dividing organisms (6 dividing in 17 organisms seen) occurred at the period of minimum concentration.

Lastly, the oscillospirae again showed two peaks in concentration, the peak accompanying the maximum trichome length being associated with the major feeding period (Figs. 2, 4).

From the previous work (Warner, 1962, 1966a) and the present study, the following tentative conclusion emerges. Whenever the daily feeding behaviour of the animal includes a major period of time during which all or most of the ration is consumed, and long periods during which little or nothing is consumed, then the patterns of change of concentration of the rumen micro-organisms are characteristic of the species of micro-organism and little affected by the nature or amount of the diet. Penned animals fed a restricted diet once daily have patterns of rumen microbial concentration changes similar to those patterns found in animals eating to appetite in natural circumstances, so that studies under these strictly controlled conditions have considerable relevance to the relatively uncontrollable natural situation.

Thanks are due to Dr J. P. Hogan and Mr R. H. Weston for access to their sheep, and to Mr K. R. Ayers for technical assistance. 


\section{REFERENCES}

ArNold, G. W. (1962). The influence of several factors in determining the grazing behaviour of border Leicester $\times$ Merino sheep. J. Br. Grassld Soc. 17, 41 .

BAILEY, C. B. (1961). Saliva secretion and its relation to feeding in cattle. 3. The rate of secretion of mixed saliva in the cow during eating, with an estimate of the total daily secretion of mixed saliva. Br. J. Nutr. 15, 443.

Chapman, J. A., Murray, R. G. E. \& Salton, M. R. J. (1963). The surface anatomy of Lampropedia hyalina. Proc. R. Soc. B 158, 498.

Hogan, J. P. (1964). The digestion of food by the grazing sheep. 1. The rate of flow of digesta. Aust. J. agric. Res. 15, 384.

Hughes, G. P. \& REID, D. (1951). Studies on the behaviour of cattle and sheep in relation to the utilization of grass. J. agric. Sci., Camb. 41, 350 .

Huld, J. L., Lofgreen, G. P. \& MeYer, J. H. (1960). Continuous versus intermittent observations in behaviour studies with grazing cattle. J. Anim. Sci. 19, 1204.

Meyer, R. M., Bartley, E. E., Morrit, J. L. \& Stewart, W. E. (1964). Salivation in cattle. I. Feed and ruminal factors affecting salivation and its relation to bloat. $J$. Dairy Sci. 47, 1339.

Morr, R. J. \& Masson, M. J. (1952). An illustrated scheme for the microscopic identification of the rumen micro-organisms. J. Path. Bact. 64, 343.

Pringsherm, E. G. (1955). Lampropedia hyalina Schroeter 1886 and Vannielia aggregata n.g., n.sp., with remarks on natural and on organized colonies in bacteria. J. gen. Microbiol. 13, 285.

Stacy, B. D. \& Warner, A. C. I. (1966). Balances of water and sodium in the rumen during feeding; osmotic stimulation of sodium absorption in the sheep. Q. Jl exp. Physiol. 51, 79.

ULYATT, M. J. (1964). The use of polyethylene glycol as a marker for measuring rumen water volume and the rate of flow of water from the rumen of grazing sheep. N.Z. $J l$ agric. Res. 7, 713.

WARNER, A. C. I. (1962). Some factors influencing the rumen microbial population. J. gen. Microbiol. 28, 129.

WARNER, A. C. I. (1966a). Diurnal changes in the concentrations of micro-organisms in the rumens of sheep fed limited diets once daily. J. gen. Microbiol. 45, 213.

WARNER, A. C. I. $(1966 b)$. Periodic changes in the concentrations of micro-organisms in the rumen of a sheep fed a limited ration every three hours. J. gen. Microbiol. 45, 237. 